\title{
Políticas públicas e turismo: avaliação da participação e das instâncias de governança em Abaetetuba (Pará, Brasil)
}

\section{Public Policies and Tourism: Assessment of Instances Governance Participation in Abaetetuba (Pará, Brazil)}

\author{
Kassia Suelen da Silva Farias (FARIAS, K. S. da S.) ${ }^{*}$ e \\ Silvio Lima Figueiredo (FIGUEIREDO, S. L.)
}

RESUMO - Neste estudo ${ }^{1}$ se objetivou ampliar as discussões sobre as políticas de turismo do município de Abaetetuba (Pará, Brasil), bem como apresentou resultados acerca das políticas de turismo no estado do Pará, mais especificamente no município de Abaetetuba e identificou as articulações entre ações governamentais e organizações comunitárias, e de sua importância para o desenvolvimento sustentável do turismo. Para isso, a análise utilizou-se da pesquisa exploratória referente à relação entre governança e governabilidade, participação, turismo e políticas públicas. Também foram coletados e comparados dados por meio da pesquisa de campo, na qual o pesquisador pôde verificar o nível de participação social quanto ao desenvolvimento do turismo. Para levantamento dos dados, foram elaborados questionários, estruturados em perguntas abertas e fechadas, voltados para os representantes do poder público (Diretoria de Turismo de Abaetetuba - ABAETUR) e do $3^{\circ}$ setor (Associação dos Artesãos de Miriti de Abaetetuba - ASAMAB). A análise teve como pressuposto a matriz de Elementos da Governabilidade no Turismo, elaborada por Nóbrega (2012), analisando-se a "Participação qualitativa entre os membros da instância". A pesquisa pôde constatar a inexistência de instâncias no município, o que caracterizou a baixa participação qualitativa entre as organizações civis, privadas e o poder público. Isso repercutiu, decisivamente, no mau desempenho da atividade em Abaetetuba-Pa.

Palavras-chaves: Instâncias de Governança; Governabilidade; Participação; Políticas Públicas de Turismo.

\footnotetext{
* Formação: Graduação em Turismo (Bacharelado) pela Universidade Federal do Pará (UFPA); Especialização em Planejamento e Gestão Pública do Turismo e do Lazer (UFPA/Núcleo de Altos Estudos Amazônicos/(NAEA); Mestranda em Planejamento do Desenvolvimento (UFPA/Núcleo de Altos Estudos Amazônicos/NAEA). Endereço físico para correspondência: Rua vitória Régia 83. CEP: 66079-450 - Belém - Pará (Brasil). E-mail: kassiasfarias@ gmail.com

** Formação: Graduação em Turismo (UFPA). Mestrado em Planejamento (UFPA/NAEA). Doutorado em Comunicação pela Universidade de São Paulo (USP/ECA); realizou estágio pós-doutoral em sociologia na Université René Descartes - Paris V Sorbonne. Atividade profissional: Professor/pesquisador do Núcleo de Altos Estudos Amazônicos da Universidade Federal do Pará (NAEA/UFPA). Professor Visitante do Programa de Pós-Graduação em Turismo da Universidade Federal do Rio Grande do Norte (UFRN). Endereço físico para correspondência: NAEA/UFPA. Av. Perimetral, Número 1 - Guamá. CEP: 66075-750 - Belém - Pará (Brasil). E-mail: slima@ ufpa.br

${ }^{1}$ Pesquisa realizada com o apoio do Conselho Nacional de Desenvolvimento Científico e Tecnológico CNPQ (Edital Universal) para o projeto Cadeia Produtiva do Turismo: Governança e Governabilidade em Cidades Médias Turísticas, coordenado pelo prof. Silvio Lima Figueiredo, grupo de pesquisa: Turismo, Cultura e Meio Ambiente do NAEA/UFPA, e bolsa PIBIC/CNPQ.
} 
ABSTRACT - This study aimed to broaden discussions on the Abaetetuba (Pará, Brazil) tourism policies, and it presented results about tourism policies in Pará State, more specifically in the town of Abaetetuba and identified the links between governmental actions and community organizations, and its importance for sustainable development of tourism. For this analysis it was used exploratory research related to the relationship between governance and governability, participation, tourism and public policies. It was also collected and compared data using field research, where the researcher was able to verify the level of social participation in the development of tourism. For data collection, it was prepared questionnaires structured in open and closed questions conducted with government representatives (Tourism Board of Abaetetuba - ABAETUR) and the 3rd sector (Association of Craftsmen Miriti Abaetetuba - ASAMAB). The analysis had as assumption the Tourism Governability Elements matrix, prepared by Nóbrega (2012), which analyzed the "qualitative participation among members of the Instance". The research has noted the lack of instances in the municipality, which characterized the low qualitative participation between civil society, private and public organizations. This reflected decisively in the poor performance of the tourism activity in Abaetetuba-Pa.

Key words: Governmental Instances; Governance; Participation; Tourism Public Policies. 


\section{INTRODUÇÃO}

O Turismo tem sido reconhecido como uma atividade que vai além das questões econômicas, pois se relaciona direta e indiretamente às diferentes práticas sociais que proporcionam novas experiências e vivências. Dessa forma, ele é caracterizado em diversos estudos como um fenômeno sociocultural, principalmente nos estudos que o compreende na confluência de diferentes aspectos: econômicos, sociais, ambientais e políticos.

Por se tratar de uma atividade complexa, diagnósticos criteriosos que subsidiem o planejamento e o desenvolvimento desse fenômeno e sua relação com o planejamento e desenvolvimento regional estão, cada vez mais, sendo tratados nos estudos sobre o turismo. O acompanhamento das ações públicas e, até mesmo, da iniciativa privada se tornaram constantes, principalmente após diversas pesquisas identificarem as falhas na formulação e implementação dos planos, programas e projetos de turismo em diversas regiões do Brasil (FIGUEIREDO et al., 2013, TOMAZZONI, 2009, NÓBREGA, 2012).

O turismo apresenta-se atualmente de igual forma como uma das atividades econômicas com potencialidade de ser explorada na região Amazônica, apontada como um caminho de desenvolvimento sustentável por meio do ecoturismo, uma vez que uma das suas principais matérias primas é a floresta preservada, ou com poucas intervenções. No entanto, apesar do potencial para o desenvolvimento da atividade turística no Estado do Pará, permanecem grandes entraves que dificultam a sua execução. Dentre as problemáticas encontradas, a falta de articulação entre os envolvidos (direta ou indiretamente) está entre as principais causas do mau desempenho da atividade na região.

O Ecoturismo vem sendo apontado, desde a década de 1980 (FIGUEIREDO, 1999), como uma oportunidade de desenvolvimento da região de forma sustentável, porém, ao longo dos anos, o que se observa é uma latente desigualdade gerada a partir do desenvolvimento de algumas ações turísticas que pouco condiz com o conceito. As principais questões que precisam ser desenvolvidas se referem à efetiva participação das comunidades no planejamento e na gestão das atividades ecoturísticas (FIGUEIREDO et al., 2013) e uma reformulação dos arranjos institucionais que possam efetivar maior participação dos seus envolvidos, garantido governança (NÓBREGA, 2012). 
A descentralização, caracterizada por uma participação crescente das regiões, estados e municípios na elaboração de políticas de turismo, começou a ser compreendida como critério relevante para o planejamento da atividade, principalmente a partir de 1995, quando a Política Nacional de Turismo criou o Plano Nacional de Municipalização de Turismo (PNMT) para "incentivar as atividades do Conselho Municipal de Turismo, difundir os modelos de conselhos, fundos e outros instrumentos de municipalização" (EMBRATUR, 1996). Desde então, a participação e descentralização da gestão pública constituiu a principal estratégia da política de turismo.

Após a instituição do Ministério de Turismo em 2003, o Governo Federal lançou o Programa de Regionalização do Turismo - Roteiros do Brasil, pautado nas orientações contidas no Plano Nacional de Turismo (PNT) 2003-2007 (FIGUEIREDO; NOBREGA, 2015). A proposta era fortalecer os grupos que representavam a cadeia produtiva do turismo (público, privado e sociedade civil organizada) de forma a garantir a governabilidade entre as instâncias de governança a partir do fortalecimento do processo de gestão compartilhada entre o Governo Federal, Estadual, Municipal e as instâncias como Conselho Nacional de Turismo (CNT), Fórum Nacional de Turismo (FORNATUR), fóruns e conselhos estaduais.

No Estado do Pará foram definidos apenas 3 roteiros que se direcionavam para essa proposta. Estes por sua vez situando-se nos polos em que as políticas de fomento do turismo estavam mais desenvolvidas: Tapajós, Marajó e Belém (PARÁ, 2011). No presente trabalho, no entanto, se dará ênfase ao Polo Araguaia Tocantins, em especial o município de Abaetetuba, que, apesar de não ser alvo prioritário das políticas de turismo do Estado, possui um grande potencial para desenvolver a atividade turística, com atrações de destaque nacional, como os brinquedos de miriti.

O município de Abaetetuba localiza-se na região Nordeste do Pará e também é conhecido popularmente como "Abaete", segundo Ferreira Junior (2014). O lugar tem destaque na produção de brinquedos de miriti (muito comercializados na época do círio de Nazaré em Belém), que é um dos principais atrativos da região, dando origem inclusive ao já conhecido "Festival do Miriti", além de outras particularidades (FERREIRA JUNIOR, 2014). O miriti (Mauritia flexuosa L.f) é uma palmeira que fornece uma bucha fibrosa, leve, macia e flexível e que tem vários usos na região norte 
do país e é também encontrada nas regiões nordeste e centro-oeste do país (buriti) e é comum em várzeas baixas e áreas alagadiças, com a altura podendo atingir de 20 a 35 metros (FERREIRA JUNIOR, 2014).

Neste estudo se teve como intenção apresentar resultados acerca das políticas de turismo no estado do Pará, mais especificamente no município de Abaetetuba, identificando as articulações entre ações governamentais e organizações comunitárias, e de sua importância para o desenvolvimento sustentável do turismo. O estudo vem sendo desenvolvido desde 2009 e, no primeiro momento da pesquisa, a análise atingiu os municípios de Santarém, Belterra e Monte Alegre, no Oeste do Estado do Pará. A segunda etapa da pesquisa se concentrou em municípios próximos a Belém, capital do Estado e durou dois anos, entre 2012 e 2013. Nesse sentido o município de Abaetetuba desempenha papel importante na espacialidade da cadeia produtiva e da gestão pública do Programa de Regionalização do Turismo, logo sua análise dentro desse processo foi supostamente fundamental.

Para o alcance de tais objetivos, utilizou-se como procedimento de pesquisa a investigação bibliográfica, referente a conceitos e categorias como turismo e políticas públicas, e o debate sobre a participação social no desenvolvimento do turismo. A pesquisa documental possibilitou compreender a participação social nas políticas de desenvolvimento do turismo na região Tocantins como um todo. A partir da análise bibliográfica e documental, foi possível a identificação e comparação de dados por meio da pesquisa de campo, com o objetivo de identificar as políticas públicas específicas para Abaetetuba, e a relação com as questões de desenvolvimento e participação. Para levantamento dos dados, foram aplicados questionários estruturados em perguntas abertas e fechadas aos diferentes agentes envolvidos com o desenvolvimento do turismo no município. A análise teve como pressuposto orientador a matriz de Elementos da Governabilidade no Turismo, elaborada por Nóbrega (2012), particularmente as questões relativas à Participação Qualitativa, pois foi considerada de suma importância para a análise de formação da ideia de governança trabalhada por Souza (2000) e para os objetivos da presente investigação.

Pesquisa essa que fez parte de projeto de pesquisa "Cadeia Produtiva do Turismo: Governança e Governabilidade em Cidades Médias Turísticas”, realizado com 
o apoio do Conselho Nacional de Desenvolvimento Científico e Tecnológico - CNPQ, vinculada à Universidade Federal do Pará.

\section{GOVERNANÇA E GESTÃO PÚBLICA DE TURISMO NA AMAZÔNIA}

É recente a preocupação das políticas públicas com a lógica interna dos agentes sociais. Segundo Schneider (2005), isso se intensificou a partir da década de 1980 quando pesquisadores analisaram os fenômenos sociais sob uma perspectiva micro (teoria sistêmica cibernética), ou seja, como resultados da ação de indivíduos e atores coletivos. Essa questão passou a ser ampliada e reproduzida conduzindo ao entendimento do conceito de governança. Schneider (2005, p. 33) conceitua o termo governança como "cibernética institucional, centrada em atores". Por esse motivo, a governança não está limitada aos preceitos do Estado, mas é compreendida como um processo de condução da sociedade por meio de instituições e atores sociais. Assim, conceito de governança refere-se principalmente a um certo modus operandi das políticas governamentais e influi na relação governo - sociedade e na condução das políticas (SANTOS, 1997 apud SILVA; MELO, 2000)

A implementação das políticas públicas está fortemente imbricada em estruturas de governança, pois, em regra, ela é entendida como um processo associado aos "arranjos institucionais que dão sustentação à cooperação, à coordenação e à negociação" (SILVA; MELO, 2000, p. 15). Para Silva e Melo (2000) isso evidencia o entendimento de que a implementação desses dispositivos é um processo de aprendizagem estruturado fundamentalmente por meio de uma rede de agentes públicos, sejam agentes governamentais ou não, que proporcionam a descentralização.

Observa-se, então, uma nova interpretação dos pesquisadores das ciências humanas, das ciências sociais aplicadas e das ciências políticas sobre a definição dos atuais mecanismos e dispositivos do Estado. Diferente das visões tradicionais, relativas à formulação e implementação das políticas públicas de forma centralizada e de cima para baixo (to down), as instituições e agentes públicos são apontados como importantes partícipes que fortalecem o processo de descentralização do poder público por meio da transferência de responsabilidades. Isso implica, por exemplo, num processo de gestão 
compartilhada entre Estado, iniciativas privadas, Organizações Não Governamentais ONG's e associações.

Um policy cycle (ciclo de políticas públicas que demonstra o processo de elaboração das políticas), neste sentido, é mais bem representado por redes complexas que se articulam entre atores sociais, políticos e arranjos institucionais que formulam e implementam as decisões políticas em ambientes democráticos e descentralizados.

Os desafios das políticas públicas e suas redes, segundo diversos autores (SILVA; MELO, 2000; SCHNEIDER, 2005; AZEVEDO; ANASTASIA, 2002), são as dificuldades de implementação dos seus desdobramentos, ou seja, planos, programas e projetos, seja por não haver um monitoramento e avaliação constante ou por algum outro obstáculo burocrático de natureza variada, que dificulta a atuação dos diferentes atores que compõem essas redes complexas. Silva e Melo (2000) ressaltam que a implementação é o ponto crucial das políticas públicas, pois orienta a elaboração de novas políticas, pressupondo que a má implementação acarreta, consequentemente, a elaboração desajustada de outra política pública subsequente e reforça a rede de políticas.

[...] a formação de redes de políticas públicas pode ser vista como uma reação ao aumento da jurisdição da política estatal, à crescente interdependência e ao avanço acúmulo e concentração de recursos sociais em grandes organizações (atores corporativos) (AZEVEDO; ANASTASIA, 2002, p. 39).

Observa-se que a formação das redes de políticas públicas pode ser compreendida como uma reação às políticas fracassadas do Estado. A mobilização coletiva em torno da maior eficácia na sua implementação possibilitou a criação de canais institucionalizados, legítimos do processo de articulação e cooperação dos atores sociais. Para Oliveira et al. (2015) as redes são:

[...] patrones que nacen del deseo colectivo de innovar las estructuras organizacionales que no atienden las nuevas demandas sociales o aspiraciones de un grupo. Cada red tiene una configuración particular e indica una nueva forma organizativa donde las relaciones dependen del ambiente en el que está actuando, de la cultura de sus miembros, de sus facilitadores y de los objetivos construidos colectivamente. Su composición es multisectorial y hay constantes tensiones entre las estructuras verticales y los procesos horizontales, entre competencia y cooperación (OLIVEIRA et al., 2015, p. 80). 
Observa-se, portanto, que a formação das redes origina-se sobretudo a partir de estruturas descentralizadas, nas quais diferentes aspectos (sociais, culturais e ambientais) direcionam seus objetivos. Isso significa dizer que, embora a governança seja um atributo do Estado e de seus agentes políticos, para que haja resultados eficazes os governados devem estar envolvidos e articulados de tal modo que consigam participar do processo de definição, implementação e acompanhamento (AZEVEDO; ANASTASIA, 2002).

Desse modo, o grau de participação e de envolvimento da sociedade em torno das políticas elaboradas e dirigidas por seus governantes implica na maior ou menor capacidade de governança. Além disso, Azevedo e Anastasia (2002, p. 81) afirmam que o grau de accountability e de responsiveness (prestação de contas, responsabilização e capacidade de dar respostas aos problemas da sociedade por meio de controle de políticas) afeta "os padrões de governabilidade vigentes nas diferentes sociedades". As prestações de contas e responsabilizações são, nesse sentido, dispositivos necessários de uma governança democrática, pois se referem à capacidade dos governantes agirem de forma responsável perante seus governados. Para isso, no entanto, o Estado, deve ser capaz de produzir conjuntamente políticas de cooperação entre os atores sociais.

Os atores, conforme anuncia Schneider (2005), são importantes nesse processo pois são, ao mesmo tempo, "sensores" que conseguem identificar a eficácia das políticas públicas e os outros agentes da rede. Redes de políticas públicas incorporam, assim, diversos atores, oficiais ou não, que se diferem em subsetores sociais e políticos e estão integrados unicamente na formulação e condução das políticas públicas.

No âmbito da relação entre governança e autonomia, Souza (2000) observa que esta última tem papel importante na garantia da participação e da efetiva relação entre atores sociais e políticas públicas. Souza (2000) defende dois aspectos da perspectiva autonomista para conceituá-la: a liberdade de fazer coisas e o prazer do exercício da liberdade como um valor em si mesmo. Assim, o autor apresenta a justiça social e a qualidade de vida como parâmetros que dão corpo à autonomia como controle democrático dos processos decisórios (SOUZA, 2000). Esses conceitos apresentam o cerne do debate sobre governança e participação e são tratados nas análises das políticas públicas do turismo. 
O turismo é, segundo Figueiredo e Ruschmann (2004, p. 15), "uma forma de viagem exclusiva da modernidade e pilar da pós-modernidade", que se caracteriza por ser uma atividade complexa, pois, envolve diferentes atores. A busca por melhor compreensão do fenômeno tem orientado diferentes pesquisas ao longo dos anos; dentre elas, destacam-se as abordagens socioantropológicas que avaliam a viagem como rito de passagem, considerando as motivações e as implicações socioculturais a partir da viagem e do turismo. Outra abordagem é o turismo como atividade econômica, identificando-a como importante instrumento para o desenvolvimento econômico de um país, como um setor da economia que produz efeitos desejáveis na criação de empregos e distribuição de renda (FIGUEIREDO; NÓBREGA, 2015). Cientes disso, Barretto (2004) e Figueiredo et al. (2013) enfatizam a necessidade de estudar/compreender o turismo em um mix de abordagens multidisciplinar e interdisciplinar que dão base para a sua organização e seu planejamento.

O planejamento dessa atividade requer um alto grau de participação do Estado, do setor privado e da sociedade civil organizada no que se refere à criação de instrumentos legais que orientem o seu desenvolvimento. A sinergia e o comprometimento entre as partes interessadas são um fator indispensável para que a atividade consiga desenvolver um determinado local, superando conflitos.

A atividade turística é amplamente reconhecida como uma atividade econômica com alta potencialidade de gerar empregos, rendas, divisas e receitas quando bem conduzida. Mcintosch et al. (2002) ressalta que tais benefícios dependem diretamente da possibilidade da economia local produzir bens e serviços que consigam deter o "olhar" do turista para a região, ou seja, na capacidade de gerar um efeito multiplicador para os diversos setores envolvidos como hotéis, restaurantes, empresas de transportes, comércio, agências de viagens e outros.

\footnotetext{
Para que os benefícios totais ocorram nas localidades é necessário que haja os "vazamentos" dos efeitos, que decorrem do grau de interação intersetorial existente na região, avaliada em geral a parir das matrizes de input-output e dos multiplicadores de renda e emprego (NÓBREGA, 2013, p. 102).
}

Ao longo dos anos, diferentes preocupações acerca do desenvolvimento do turismo foram discutidas. Debates referentes à questão ambiental e social do desenvolvimento do turismo se tornaram cada vez mais frequentes e implicaram 
fortemente numa reordenação das políticas de turismo no Brasil. Com a criação do Ministério do Turismo, o Governo Federal passou a preconizar a regionalização como estratégia fundamental para o desenvolvimento turístico no território nacional e criou, em 2004, o Programa de Regionalização, também incorporado ao PNT de 2007 (BRASIL, 2003; 2007). No Programa de Regionalização do Turismo verificou-se que em vários sentidos se enfatiza a descentralização das ações; a revalorização dos lugares e territórios; a emergência da dimensão local com participação dos residentes, por meio da representação de diferentes atores da sociedade em instâncias de governança, no intuito de aproximar mais os interesses de diferentes grupos sociais; dar maior celeridade às tomadas de decisões e garantir o provimento de recursos direcionados ao desenvolvimento do turismo regional. Os fóruns e conselhos são instâncias que precisariam ser fortalecidas (BRASIL, 2010).

Segundo Oliveira et al. (2015, p. 80) "La integración de los sectores público, privado y tercer sector surge como presupuesto del proceso de regionalización del turismo. No entanto, o envolvimento dos diversos atores da cadeia produtiva do turismo de forma participativa, conforme apontam Nóbrega (2012) e Miranda Castro e Midlej (2013) é uma prática que ainda apresenta distorções, pois se vivenciam na sociedade brasileira decisões públicas ainda enraizadas em uma história de práticas extremamente centralizadoras, mesmo com os avanços recentes.

Torna-se indispensável, portanto, a eficácia na formulação, implementação e avaliação de políticas públicas que assegurem a sustentabilidade das atividades turísticas, tendo em conta a justa distribuição dos benefícios para a sociedade e a proteção adequada do ambiente natural e cultural da área anfitriã (MIRANDA CASTRO; MIDLEJ, 2013, p. 682).

Planos, programas e projetos referentes a essa atividade compreendem, teoricamente, a importância desses discursos e buscam inovar para que as ações relativas à participação sejam eficazes. Nessa mesma chave, no atual Plano Nacional de Turismo 2013 - 2016 se busca a seguinte estratégia:

Sensibilização e mobilização dos atores sobre a importância da descentralização, participação e integração das políticas públicas do setor, apoio e fortalecimento ao Sistema Nacional de Turismo, que abrange os órgãos oficiais e instâncias de governança estaduais, municipais, regionais e macrorregionais, a partir do Conselho Nacional de Turismo. Este processo deve ocorrer por meio de ações de planejamento e capacitação institucional [...] (BRASIL, 2013, p. 47). 
Os objetivos que buscavam desenvolver a atividade de forma descentralizada e com maior participação dos atores locais passaram a orientar definitivamente as políticas públicas de desenvolvimento do turismo a partir de 2003, com o Programa de Regionalização de Turismo (PRT) - Roteiros do Brasil, pautado nas orientações contidas no Plano Nacional de Turismo (PNT) 2003-2007 (BRASIL, 2003). Com o lançamento do PNT 2007-2010, denominado de "Turismo - uma viagem de inclusão", o PRT migra de programa de "Roteiros Integrados" para "Política de Desenvolvimento do Turismo", ou seja, passou a integrar os sete macroprogramas do Plano, o macroprograma de Estruturação e Diversificação da Oferta Turística (BRASIL, 2007).

\section{CARACTERIZAÇÃo da CADEIA PROdUTIVA E AVALIAÇÃo DAS INSTÂNCIAS DE GOVERNANÇA NO MUNICÍPIO DE ABAETETUBA- PA}

O município de Abaetetuba (Mapa 1) compõe a Região do Tocantins no estado do Pará, cujas transformações econômicas, sociais e territoriais acompanharam os eventos políticos que marcaram a história do período colonial e pós-colonial na Amazônia. Inicialmente essa região foi marcada pelo intenso processo de extração de drogas do sertão, e pela ocupação portuguesa com a formação de núcleos populacionais ao longo do rio Amazonas e de outros rios, que subjugou e escravizou a população indígena autóctone. Posteriormente, a região passou por intensa transformação, sobretudo com a formação de uma elite local sustentada por economias extrativas da borracha e da castanha do Pará, entre outras, com mão de obra de escravos africanos (PARÁ, 2009).

Inicialmente, o município foi designado como um distrito subordinado ao município de Belém, sua primeira denominação foi Abaeté, topônimo indígena que significa "homem forte e valente". Porém, por haver outra cidade Brasileira com o mesmo nome, em 1944, Abaeté passou a ser chamado de Abaetetuba, de origem tupi que significa "lugar de homem ilustre" (IBGE, 2014).

Localizado no nordeste do Pará, Abaetetuba tem cerca de 147.000 habitantes numa área de 1.610,408 km² (IBGE, 2014) e setor terciário (comércio e serviços) é responsável pela sua dinâmica econômica. O município é reconhecido pela produção de 
brinquedos de miriti, os quais constituem, desde 1905, uma das principais tradições relacionadas ao Círio de Nazaré, pois são anualmente produzidos em Abaetetuba e vendidos em Belém durante os festejos do Círio (IPHAN, 2004).

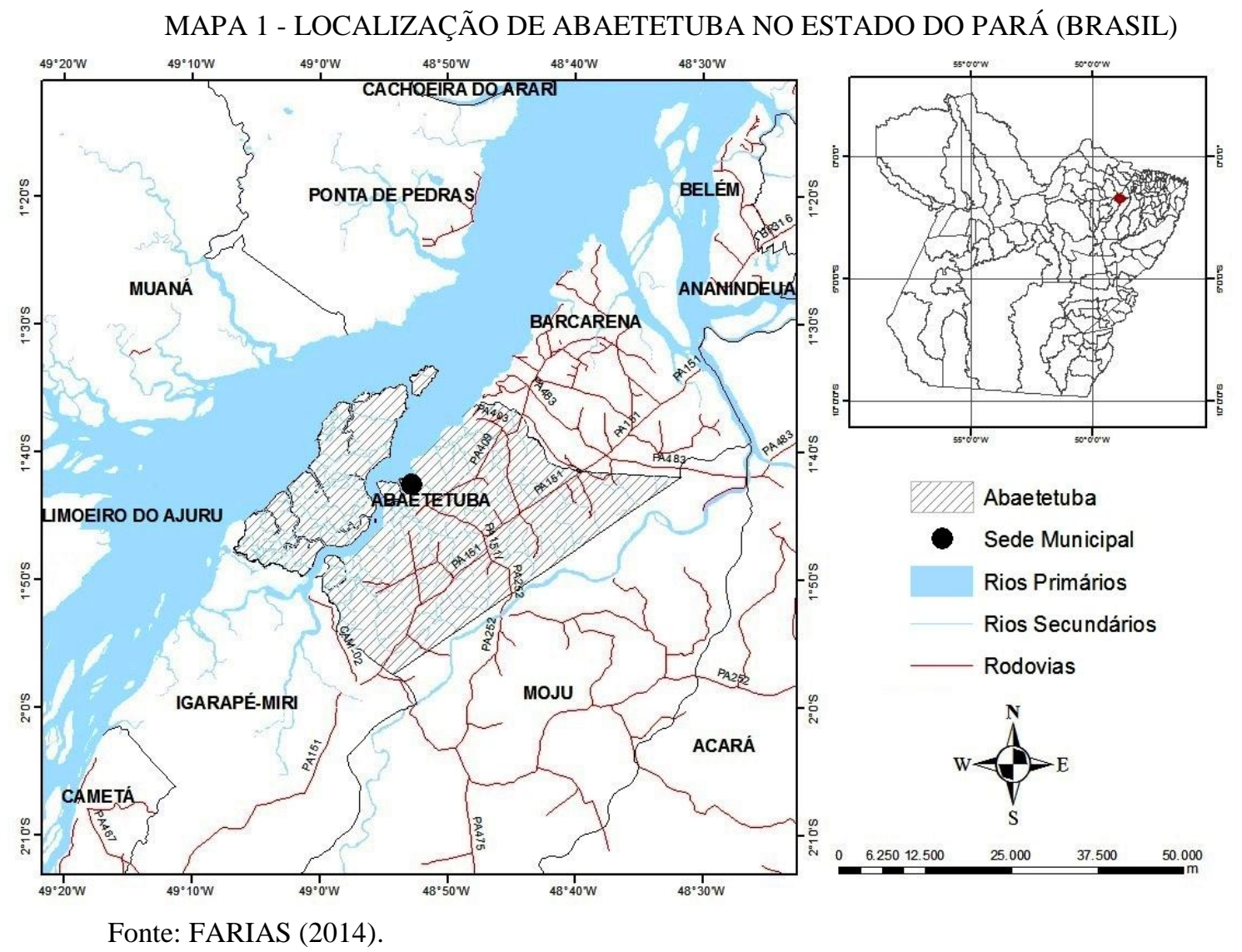

O vale do Rio Tocantins, onde o município se localiza, foi caracterizado durante os séculos XVII e XVIII pela produção agrícola baseada no sistema plantation, no qual o cultivo de cacau e cana de açúcar eram os principais produtos econômicos da região (PARÁ, 2009). A formação de fazendas e de engenhos, acompanhada pela introdução de escravos e a submissão de indígenas ao trabalho guardam a estreita relação que os remanescentes de quilombo do local tiveram com as transformações econômicas, sociais e espaciais ocorridas na região e até 2015 o município contava com 16 povoados rurais remanescentes de quilombos: Moju (22), Oeiras do Pará (19) e Baião (18) (PARÁ, 2009).

Conforme o Plano de Desenvolvimento Regional Sustentável de TocantinsPDRS, a região caracteriza-se por deter uma pequena parte dos seus recursos turísticos explorada (PARÁ, 2009). A proximidade de Belém, a facilidade de acesso (rodoviário - 
Alça Viária; ou fluvial - baía do Guajará), assim como uma diversidade de atrações como a produção de artesanatos de miriti (Figura 1), praias e igarapés (Figura 2), fazem de Abaetetuba um município com potencial para a atração de turistas. Contudo, ainda há pouca participação dessas atrações na cadeia produtiva local do turismo, o que faz das pesquisas sobre o setor um importante instrumento para identificar as falhas e propor soluções para o seu melhor desenvolvimento.

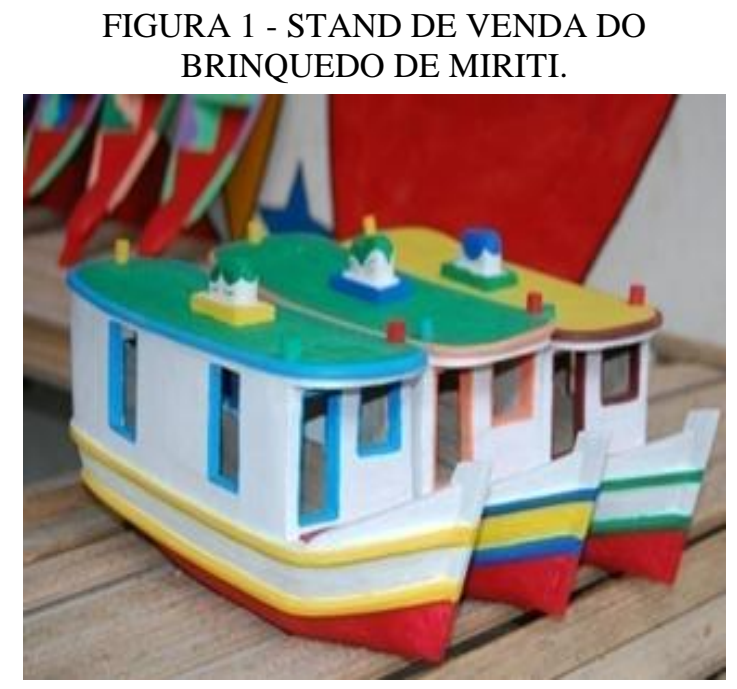

Fonte: ABAETEUBA, 2013.
FIGURA 2 - VISTA DA PRAIA DE BEJA E DA ORLA

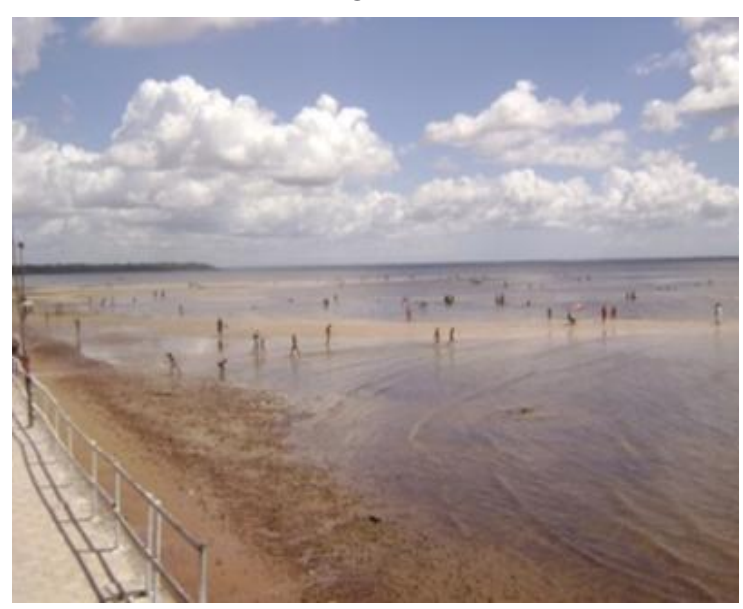

Fonte: ABAETEUBA, 2013.

É possível identificar na cadeia produtiva do turismo em Abaetetuba alguns setores importantes para o desenvolvimento da atividade na região. Bares, Restaurantes, Hotéis com diferentes tipos de acomodações estão presentes no município. Observouse, porém, que apesar da existência de serviços importantes para a atividade turística inexistiam operadoras de turismo, um importante canal que facilita a relação entre a oferta e a demanda turística. A Associação dos Comerciários de Abaetetuba (ACA) é instrumento de representatividade das empresas do setor, como hotéis, bares e restaurantes, no entanto poucas empresas ligadas a essa atividade estavam associadas, dentre elas o restaurante J.B Porto; o restaurante Casarão e o hotel Tropical.

Sobre os serviços existentes no município, o inventário realizado pela Diretoria de Turismo no período de 03/01/2013 a 07/03/2013 demonstrou que:

[...] alguns hotéis e restaurantes, necessitam de melhoria da prestação de serviços principalmente em sua estrutura ou de atendimento. Os melhores hotéis apresentam uma boa estrutura para os segmentos onde atuam, principalmente em turismo de negócios ou de eventos técnicos e científicos, 
entretanto, a grande maioria não obteve resultados satisfatórios na avaliação de campo, pois apresentam muitos problemas de ordem de adequação arquitetônica, conforto térmico, localização, serviços diversificados, atendimento, paisagísticos, gestão, entre outros problemas (ABAETETUBA, 2013, p. 25).

Os planejadores das políticas públicas de turismo do Estado do Pará têm dado pouca importância para a região Tocantins. A ação mais recente criada para os municípios que a compõem foi o roteiro internacional Amazônia Quilombola, no município do Acará e a Rota do Açaí, que inclui os municípios de: Belém, Barcarena, Abaetetuba, Moju e Igarapé-Miri (PARÁ, 2009). Sobre a importância de desenvolver a atividade na região, no Plano de Desenvolvimento Regional Sustentável da Região do Tocantins/PA (PARÁ, 2009) se ressalta que:

\begin{abstract}
O turismo deve ser desenvolvido na região basicamente por duas razões: pela existência do fluxo regional em função da qualidade mediana das atrações e das condições de acesso, a partir de Belém, o principal emissor de turistas; e pela possibilidade de geração de emprego e renda para a população local, como alternativa às atividades e composição de arranjos que tenham a possibilidade da sazonalidade (PARÁ, 2009, p. 54).
\end{abstract}

Sobre a estrutura pública de turismo no município, verificou-se haver apenas uma diretoria que estava subordinada à Secretaria Municipal de Educação, cuja função, até então, era identificar, organizar, fomentar e divulgar Abaetetuba. Os principais projetos de fomento dessa atividade, no entanto, estavam presentes nos Planos de Metas de outros órgãos do município, como a Secretaria Municipal de Meio Ambiente (SEMEIA), que propõe, para a gestão atual, a elaboração do projeto de turismo ecológico na praia de Beja (ABAETETUBA, 2013). Estavam presentes também, dentro das propostas de segurança para o município, projetos de aumento da iluminação pública nos monumentos, parques, praças e nas áreas de maior circulação da sede municipal, estimulando a sociabilidade e o turismo. Dessa forma, foi possível perceber que eram poucas as ações na área da cultura e lazer que corroboravam para desenvolvimento do turismo no município (ABAETETUBA, 2013).

Sobre o fluxo e perfil de turistas, os documentos orientadores da Diretoria de Turismo de Abaetetuba (ABAETUR) apresentados no Inventário Turístico e Cultural do município destacam que: 
Os fluxos turísticos atuais são provenientes em grande maioria de municípios próximos e de Belém. O mercado nacional atingindo é inexpressivo. A principal forma de organização da viagem é espontânea (sem intermédio de agências turísticas) e com utilização de veículos próprios. Sobressaem-se, ainda carências de marketing com foco na qualidade dos produtos e serviços e no alcance de novos mercados nacionais (ABAETETUBA, 2013, p. 23).

Sobre os aspectos apontados, a Diretoria de Turismo enfatiza a necessidade de se estabelecer uma rede de cooperação que consiga unificar as "políticas de infraestrutura, sanitária, ambiental, educacional e cultural" para o melhor desenvolvimento do turismo no município.

O turismo no município de Abaetetuba pode ser um grande vetor de desenvolvimento econômico e social, contudo exige um grande esforço de ações integradas que perpassam pelo fortalecimento da gestão do turismo e atração de investimentos do setor privado, bem como de sua especialização em determinados segmentos turísticos, neste caso especial o turismo cultural (ABAETETUBA, 2013, p. 25).

Para avaliar o desempenho das instâncias de governança de turismo no município de Abaetetuba, utilizou-se a matriz de Elementos da Governabilidade no Turismo, proposta por Nóbrega (2012) que considera sete elementos bases para sua construção. A matriz é um elemento de orientação para identificar as principais questões e variáveis relacionadas à governança, à governabilidade, à participação e a atuação nas e das arenas públicas no processo de planejamento e das políticas públicas do turismo (NÓBREGA; FIGUEIREDO, 2014).

Os elementos da Matriz foram analisados na sua totalidade durante a pesquisa. No presente trabalho abordou-se o item Participação Qualitativa, haja vista a importância do tema para o debate das arenas e das políticas públicas de turismo, e da centralidade dos conflitos oriundos das práticas e participações dos atores nas arenas e processos (SCHNEIDER, 2005; AZEVEDO, ANASTASIA, 2002; SILVA, MELO, 2000; SOUZA, 2000). Para a análise da variável em questão, Nóbrega (2012) identificou três níveis de participação, resultantes de um longo debate sobre o conceito de participação nos processos decisórios do planejamento e políticas públicas de turismo: 
FIGURA 3 - NÍVEIS DE PARTICIPAÇÃO DOS ATORES SOCIAIS NO PROCESSO DECISÓRIO

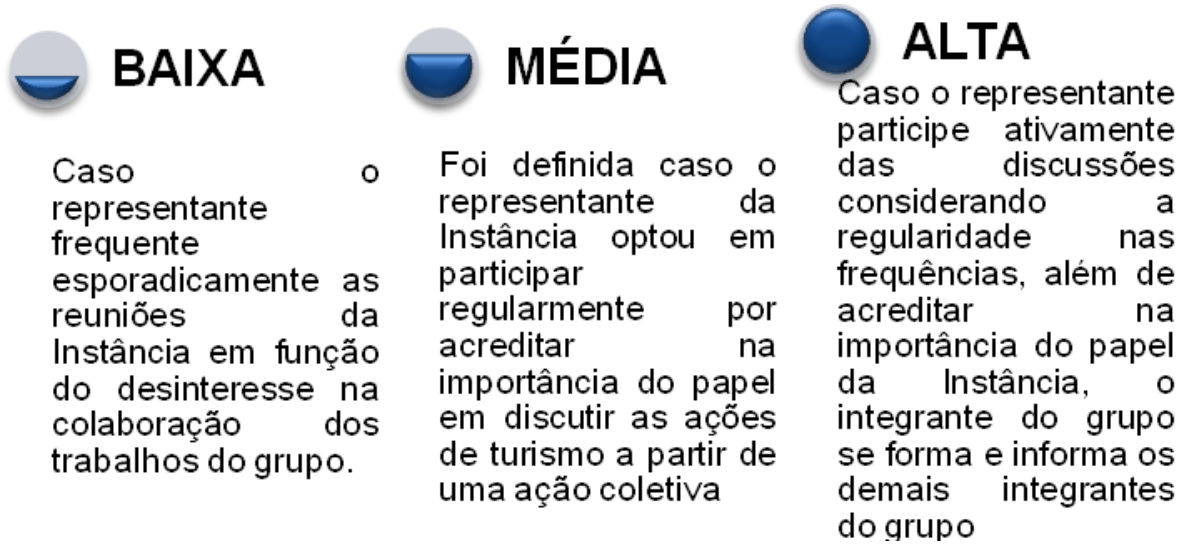

Fonte: NÓBREGA (2012) e NÓBREGA; FIGUEIREDO (2014).

\subsection{ASPECTOS METODOLÓGICOS E TÉCNICAS DE COLETAS APLICADAS}

A técnica de coleta de dados utilizada foi a observação direta e as entrevistas com informantes chaves (THIOLLENT, 1987, p. 32), pois estabelecem "um contato efetivo com as pessoas implicadas no problema investigado". Para levantamento dos dados, foram elaborados questionários estruturados em perguntas abertas e fechadas direcionados aos diferentes membros das instâncias. Para a aplicação dos questionários, foram escolhidos os seguintes representantes que faziam parte de alguma forma das reuniões e debates sobre turismo no município, dentre eles, representantes do poder público: diretora da ABAETUR, Gestora em turismo (turismóloga) funcionária efetiva da ABAETUR e presidente da Associação dos Artesãos de Miriti de Abaetetuba (ASAMAB).

Sobre a participação qualitativa dos atores na suposta instância, objeto de pesquisa deste trabalho, constatou-se a inexistência de reuniões periódicas entre os membros, já que reunir e discutir as falhas e desafios, assim como apresentar as potencialidades (atrativos turísticos) existentes no município, é um importante passo para a sociedade ampliar sua autonomia, bem como desenvolver o turismo de forma sustentável. Esse problema pôde ser constatado em uma das reuniões, no Seminário de Turismo de Abaetetuba, que ocorreu no dia 29 e 30 de maio de 2014 (FARIAS, 2014), e que foi percebido como única manifestação de um possível encontro entre os atores que faziam parte da cadeia produtiva do turismo no município. 
O seminário foi realizado em parceria com a ASAMAB, o Instituto Federal do Pará (IFPA), a Secretaria de Estado do Turismo (SETUR) e a Fundação Cultural do Município para discutir sobre o miriti como atrativo turístico de Abaetetuba. O Seminário foi, sem dúvida, um importante passo para articulação entre os diferentes setores da atividade turística do município, mas o que se observou foi a falta de interesse da grande maioria, pois poucos convidados compareceram ao seminário. $\mathrm{O}$ seminário contou com a participação de representantes da SETUR, com a proposta de apresentar aos empresários locais a grande potencialidade que o município apresentava para desenvolver a atividade turística, porém não havia nenhum representante do setor (hotelaria, restaurantes, transporte etc.). Alguns representantes do setor educacional também apresentaram aos poucos participantes a necessidade de criar um roteiro turístico do miriti, além de se estabelecer melhor organização e interação entre a associação dos artesãos com o empresariado local.

\title{
3.2 RESULTADOS
}

Quanto à análise dos questionários, inicialmente constatou-se a desarticulação do próprio setor que direcionava as estratégias de desenvolvimento do turismo. Conforme observado pela diretora da ABAETUR, o grande entrave para um planejamento adequado que fomentasse a atividade no município seria a falta de autonomia da Diretoria de Turismo “[...] o turismo não está legalizado, ele está juntamente com a Fundação Cultural. Agente é tipo..., como é? Atrelado à Fundação Cultural” (INFORMAÇÃO VERBAL, 2014) ${ }^{2}$ e apesar de haver uma diretoria direcionada somente para essa função - de desenvolver o turismo - ela não implementava projetos e não atuava como deveria.

\begin{abstract}
A diretoria de turismo ele fica dentro de uma fundação, então ele não tem fundos e não tem renda específica voltada para o turismo, então a gente auxilia o trabalho da Fundação. Quando a gente consegue uma verba ou de patrocínio, que a gente mesmo vai buscar do empresariado local, a gente tenta fazer a divulgação ou tenta participar de feiras e de algumas coisas assim, só que a gente não tem, a gente tem, por exemplo..., um conselho, mas ele não é ativo, a gente não tem fundo, a gente... o conselho também, como
\end{abstract}

\footnotetext{
${ }^{2}$ Informação obtida em entrevista com a diretora da ABAETUR em 10 de Abril de 2014. FARIAS, 2014.
} 
ele não é ativo ele não pode determinar o que a gente vai fazer (INFORMAÇÃO VERBAL) ${ }^{3}$.

A falta de autonomia da ABAETUR estava refletindo decisivamente no planejamento da atividade no município, assim como no interesse do empresariado local em investir e fomentar a atividade turística. Além disso, a relação entre os representantes da cadeia de turismo pareceu muito limitada, havendo poucas articulações entre os membros. Sobre a relação da ABAETUR com o trade de turismo local, a diretora de turismo afirmou que a relação não era fácil:

[...] os encontros são esporádicos, e quando tem a gente tem que mandar convites e quando eles vêm, vêm um, dois ou três....no carnaval é quando todo mundo vem....quadra junina também. O Miriti Festival estava sendo feito por lá...pelo miriti, de uns tempos pra cá tá sendo feito por aqui, mas quem está fazendo é a Fundação Cultural com eles lá (INFORMAÇÃO VERBAL) ${ }^{4}$.

Para o representante da Associação dos Artesãos de Miriti de Abaetetuba (ASAMAB), a relação da associação com a ABAETUR era indireta, uma vez que as reuniões e parcerias eram realizadas diretamente com a Fundação Cultural, que, como explicado anteriormente, assim como a ABAETUR, era um órgão da Secretaria Municipal de Educação.

Portanto, foi notório o inexistente diálogo entre o órgão responsável pela elaboração do planejamento do turismo do município com os representantes que utilizavam o maior atrativo turístico do local - o artesanato de miriti e o Miritifest (hoje denominado Festival do Miriti). O Miritifest é um festival realizado anualmente que já se encontrava em sua décima edição. O evento é composto por uma feira de exposição e comercialização do artesanato de miriti e de praça de alimentação com venda de comidas típicas, entre outras atrações (FERREIRA JUNIOR, 2014).

Nas palavras do presidente da ASAMAB, a importância da Associação para o turismo em Abaetetuba se dava "porque tem toda uma questão cultural, histórica né?

\footnotetext{
${ }^{3}$ Informação obtida em entrevista com a gestora em turismo, funcionária da ABAETUR em 30 de Abril de 2014. (FARIAS, 2014).

${ }^{4}$ Informação obtida em entrevista com a diretora da ABAETUR em 10 de Abril de 2014. (FARIAS, 2014).
} 
Por ser um dos símbolos do Círio. Quando se fala em Círio se fala... logo se pensa no miriti e vice-versa" (INFORMAÇÃO VERBAL, 2014) ${ }^{5}$.

Sobre os conselhos, fóruns etc., as questões referentes ao poder público e sua participação nas decisões majoritárias sobre o turismo no Pará e mesmo na Região do Tocantins se circunscrevem a uma pequena participação nas reuniões dos municípios do Polo Araguaia Tocantins, no órgão oficial do turismo do Estado do Pará, a SETUR. A gestora de turismo, funcionária da ABAETUR, informou em entrevista que também existia um conselho chamado CONDESEI que estava desativado. Segundo a funcionária, ele:

[...] foi criado, teve uma reunião, eu acho, no máximo. Teve a participação inclusive do pessoal da cultura, pessoal do miriti, mas ele não tem reuniões frequentes. Hoje ele não existe, não tem diretor, não tem reunião, ninguém decide nada. $\mathrm{O}$ conselho não existe, ele não é ativo, mas ele foi criado por estatuto, como a diretoria também foi criado (INFORMAÇÃO VERBAL).

As ações do Conselho tentaram seguir as orientações que vinham da PARATUR, até então órgão oficial do turismo, na implementação da chamada "Rota do Açaî".

[...] a gente começou a fazer reuniões dentro do CONDESEI (um consórcio que engloba os municípios do Baixo Tocantins) e aí tinham reuniões. Dentro desse consórcio têm pessoas especializadas em cada setor. Tinha pessoas especializadas, na época, de turismo e cultura. E aí a gente fazia reunião com todas as pessoas dos responsáveis pelo turismo de Barcarena, Abaetetuba, Igarapé-Miri e o pessoal daqui do Baixo Tocantins e a gente tentou fazer uma roteirização e até retomar aquele roteiro da Rota do Açaí que a PARATUR instituiu há anos atrás, mas ainda não foi possível porque a prefeitura do município é muito complicada principalmente em relação à verba e o que a gente precisa, dentro do planejamento da política pública, tudo precisa de verba e aí gera um conflito dentro da própria prefeitura na questão de onde vai sair esse dinheiro porque pra vir pra cá vai ter que sair de algum outro lugar. E aí no começo, toda vez que eu falava nisso de pensar numa política para o turismo e uma política de cultura as pessoas pensavam que a gente estava tentando virar uma secretaria, porque seria melhor, mas a gente sabe que aqui nesse momento é improvável, é inviável...e aí começavam a frear a nossa discussão (INFORMAÇÃO VERBAL) ${ }^{7}$.

\footnotetext{
${ }^{5}$ Informação obtida em entrevista com o Presidente da ASAMAB em 30 de Abril de 2014. (FARIAS, 2014).

${ }^{6}$ Informação obtida em entrevista com a gestora em turismo, funcionária da ABAETUR, em 30 de Abril de 2014. (FARIAS, 2014).

${ }^{7}$ Informação obtida em entrevista com a gestora em turismo, funcionária da ABAETUR em 30 de Abril de 2014. (FARIAS, 2014).
} 
Apesar da criação de políticas de turismo que visavam à descentralização e à consequente autonomia dos Estados e Municípios para o desenvolvimento do setor, ainda se percebia a concentração das decisões políticas e administrativas nos órgãos municipais que, por desconhecerem o turismo como uma atividade capaz de trazer benefícios econômicos, sociais, ambientais, acabava dificultando o fomento da atividade. O depoimento citado demonstra as tentativas fracassadas de implementar políticas de turismo em um município do Polo Araguaia Tocantins, e como se percebeu havia uma série de problemas burocráticos que dificultavam a tarefa. $\mathrm{O}$ comprometimento entre os envolvidos (poder público, privado e sociedade civil) foi, sem dúvida, um fator importante para sua eficácia e implicava na capacidade de governança. Além disso, o poder público tinha de ser capaz de produzir conjuntamente políticas de cooperação entre esses atores sociais, o que não se percebeu no município de Abaetetuba por não existirem instâncias de governança consolidadas no município.

A consolidação de uma estrutura de coordenação municipal, regional, estadual e nacional, proposta em 2004 pelo Programa de Regionalização do Turismo Roteiros do Brasil, incorporou em seus objetivos um ordenamento dos arranjos produtivos locais e regionais como estratégia de promover a cooperação e a parceria dos segmentos envolvidos na atividade turística (organizações da sociedade, instâncias de governo, empresário e outros) para atuar em conjunto no desenvolvimento do turismo nas diversas regiões do Brasil. Observou-se, no entanto, a carência dessas articulações no Estado do Pará, comprovado nos estudos de Nóbrega (2012) e Nascimento (2009). A inexistência ou precariedade de sistemas (fóruns, conselhos) que conseguissem articular os municípios integrados ao Polo Araguaia Tocantins inviabilizavam os objetivos que foram lançados pelo Ministério de Turismo, assim como caracterizavam uma inconstância na capacidade de governança e governabilidade do local e região.

Em Abaetetuba foi possível observar que as poucas ações que tentavam reproduzir formas modernas e não-autoritárias de governança e governabilidade para o desenvolvimento do turismo foram os encontros esporádicos, como seminários e reuniões, que não tinham o objetivo de decidir nem de elaborar propostas concretas. Apesar da existência de associações locais que representavam a sociedade civil (ASAMAB) e os empresários do setor (ACA), a comunicação entre eles era ineficiente, 
o que refletiu uma incapacidade de decidir em conjunto, como propõe o Programa de Regionalização do Turismo.

Alguns aspectos destacáveis sobre o conceito de participação elucidam, por esse lado, os principais problemas dos processos de governança e governabilidade para consolidar as políticas de turismo no município. Os debates clássicos apresentados por Demo (1993) sobre participação continuam a pautar tais problemas, relacionados com a representatividade dos atores, a legitimidade dessa participação, e a sua autossustentação. Diante dos elementos apresentados nesta pesquisa, o nível de participação qualitativa entre as organizações civis, privadas e o poder público era baixa, uma vez que as reuniões que discutissem o desenvolvimento da atividade no município eram escassas e não consolidavam as instâncias citadas e incentivadas pelo PRT. Os atores sociais principais nesse campo de relações não representavam interesses relacionados ao fomento do turismo como um todo e o agente público representado pela ABAETUR tinha problemas estruturais que impediam o estímulo às ações concretas e à participação geral dos outros atores.

Evidenciou-se da mesma forma um desinteresse por parte dos membros da cadeia produtiva de turismo no processo participativo. $\mathrm{O}$ desinteresse foi apontado em muitos estudos, entre eles o de Olival et al. (2007), como um dos principais motivos da desestruturação de processos participativos. Ele pode se originar da falta de informação, das disputas políticas presentes nos processos, ou ainda pela não efetivação das propostas consensuadas nas instâncias pelo poder público (FIGUEIREDO, 1998). Abaetetuba careceu de representantes que estivessem mais envolvidos com a atividade turística, seja por meio de maior informação sobre a atividade em outros locais ou da maior articulação para a solidificação de uma possível instância. Em todo caso, estudos como o de Ferreira Júnior (2014), demonstram que a ASAMAB possuía uma organização que, a despeito de seus problemas internos, aos poucos caminhava em direção de uma autonomia importante na condução e consolidação de aspectos e ações ligados à cultura e ao turismo no município. 


\section{CONSIDERAÇÕES FINAIS}

É notório que o desenvolvimento do turismo e sua relação com o planejamento e desenvolvimento regional estão diretamente relacionados com as feições da governança e da governabilidade nas instituições. Isto evidencia a necessidade contínua de readequação das políticas públicas para o maior envolvimento dos atores sociais nas tomadas de decisões. O turismo tem contribuições importantes para o desenvolvimento econômico mundial, assim como sua capacidade de gerar impactos sociais e ambientais, o que fortalece a necessidade de maior planejamento e da incorporação de todos os atores envolvidos no processo, e isso quer dizer a necessidade efetiva de participação política.

Os planos e programas brasileiros têm demonstrado o progresso da centralidade do turismo nas políticas federais, e diversas ações estão sendo tomadas para tentar melhorar questões relacionadas à falta de planejamento e de participação na implementação da atividade turística, muito embora a prática esteja, em alguns casos, desarticulada da teoria. É possível perceber que o viés econômico é predominante nesses planos, e tem se chocado com objetivos que buscam planejar o turismo com ênfase na responsabilidade e no compromisso com questões sociais e ambientais.

A pesquisa realizada identificou a dificuldade das relações entre ações governamentais e organizações comunitárias, e seu reflexo no desenvolvimento sustentável do turismo no município de Abaetetuba/PA (Brasil). A baixa participação dos atores sociais do turismo no município ratificou a ideia de que houve falta de articulação entre os envolvidos (direta ou indiretamente) com o setor, estando entre as principais causas do limitado desempenho da atividade na região do Tocantins/PA. Ao mesmo tempo, na complexa rede que alia políticas públicas a cadeias produtivas e seus arranjos, o órgão gestor do turismo em Abaetetuba carecia de força política e orçamento compatível com suas necessidades, pois se tratava de uma diretoria pouco ativa em função desse cenário. Ao mesmo tempo, e relacionado a isso, as empresas do setor bem como as associações relacionadas ao turismo do município, pouco se envolviam nas limitadas instâncias criadas para a participação, prejudicando a implementação das propostas de regionalização do turismo. 
Nesse contexto, os órgãos gestores municipais precisariam ganhar força, com a criação de órgãos específicos para o gerenciamento de ações na área ou na efetiva contribuição de departamentos e divisões das secretarias municipais, pois, nos planos e programas estaduais, não houve um incentivo à organização e ao planejamento do turismo em regiões com fragilidades de governança, e muitas vezes, ignorou áreas de importantes atrações e de potenciais turísticos, como se pôde perceber no polo Araguaia Tocantins, e especialmente no município de Abaetetuba.

No campo turístico do Estado do Pará, a fragilidade é percebida a partir da visão limitada que o Estado tem sobre a atividade, isso porque, apesar de diversos estudos científicos apresentarem necessidade de se repensar a epistemologia do turismo, e a participação dos atores nos processos, as políticas públicas geralmente incorporam essas ideias de forma superficial, limitando o entendimento sobre o turismo apenas no viés econômico, para se alcançar desenvolvimento pela geração de emprego e renda. A dificuldade de envolver os diferentes atores nesse processo indica, portanto as falhas no planejamento do turismo no Brasil.

\section{REFERÊNCIAS}

ABAETETUBA. Inventário Turístico e Cultural do Município de Abaetetuba. Abaetetuba- PA, 2013.

AZEVEDO, S.; ANASTASIA, F. Governança, "Accountability" e Responsividade: reflexões sobre a institucionalização da participação popular em experiências desenvolvidas em Minas Gerais. Revista de Economia Política, v. 22, n. 1, 85, 2002.

BARRETTO, M. Manual de iniciação ao estudo do turismo. 10. ed. Campinas. São Paulo, 2004.

BRASIL. Ministério do Turismo. Plano Nacional do Turismo: diretrizes, metas e programas, 2003 - 2007. Brasília: Ministério do Turismo, 2003.

Ministério do Turismo. Plano Nacional do Turismo, 2007 - 2010. Brasília: Ministério do Turismo, 2007.

Ministério do Turismo. Plano Nacional do Turismo, 2013 - 2016. O Turismo

fazendo muito mais pelo Brasil. Brasília: Ministério do Turismo, 2013. 
Ministério do Turismo. Programa de regionalização do turismo - Roteiros do Brasil: módulo operacional 7 - Roteirização Turística. Brasília, DF, 2010.

DEMO, P. Participação é conquista. São Paulo: Cortez, 1993.

EMBRATUR. Programa Nacional de Municipalização do Turismo - Procedimentos. Brasília, 1996.

FARIAS, K. S. da. S. Cadeia Produtiva do Turismo no Pará: Governança e Governabilidade em Abaetetuba. Relatório técnico científico do programa institucional de bolsas de iniciação científica - PIBIC/ CNPq, 2014.

FERREIRA JUNIOR, A. Entalhadores do efêmero: vida associativa na atividade artesanal com a fibra do miriti no município de Abaetetuba, Pará. 2014.75 f. Projeto de Dissertação (Mestrado) - Universidade Federal do Pará, Núcleo de Altos Estudos Amazônicos, Programa de Pós-graduação em Desenvolvimento Sustentável do Trópico Úmido, Belém, 2014.

FIGUEIREDO, S. L. Mecanismos de participação popular em turismo: a experiência da Belém do Pará. In: CORIOLANO, L. (Org.). Turismo com Ética. 1. ed. Fortaleza: Ed. UECE, 1998. p. 374-389.

Ecoturismo, festas e rituais na Amazônia. Belém: NAEA/UFPA, 1999.

FIGUEIREDO, S. L.; RUSCHMANN, D. V. M. Estudo genealógico das viagens, dos viajantes e dos turistas. Novos Cadernos NAEA, v. 7, p. 171-203, 2004.

FIGUEIREDO, S. L.; AZEVEDO, F. F; NÓBREGA, W. R. de M.; MARANHÃO, C. H. da S. Turismo em foco: globalização e políticas públicas. In: AZEVEDO, F. F.; FIGUEIREDO. S. L; NÓBREGA, W. R. de M; MARANHÃO, C. H. da S (ORG). Turismo em foco. Belém: NAEA, 2013. p. 11-27.

NOBREGA, W. R. M. Turismo e desenvolvimento regional: conceitos e políticas em um caso brasileiro. In: FIGUEIREDO, S. L.; AZEVEDO, F. F.; NOBREGA, W. R. M. (Org.). Perspectivas contemporâneas de análise em turismo. Belém: NAEA, 2015. p. 11-37.

IBGE. Cidades. Disponível em:

<http://cidades.ibge.gov.br/painel/historico.php?lang=\&codmun=150010\&search=para| abaetetuba|infograficos:-historico>. Acesso em: 29/07/2014.

IPHAN. Dossiê Círio de Nazaré. Patrimônio Histórico e Artístico Nacional/IPHAN, $2^{\text {a }}$ Superintendência Regional/ Pará-Amapá SR, 2004.

MIRANDA CASTRO, F. M. de; MIDLEJ, M. M. C B. Planejamento e Sustentabilidade: uma análise da gestão do turismo 2006-2008 a partir das representações dos termos Dendê, CVI E Maricultura no município de Valença/Bahia. Turismo em Análise, v. 24, n. 3, dez., 2013. 
MCINTOSH, R; GOELDNER, C. R.; RITCHIE, J. R. B. Turismo: princípios, práticas e filosofias. Porto Alegre: Bookman, 2002.

NASCIMENTO, V. L. Q. Políticas Públicas de ecoturismo e participação: a trajetória do PROECOTUR no Polo Belém/Costa Atlântica. 2009. 212 f. Dissertação (Mestrado) Universidade Federal do Pará, Núcleo de Altos Estudos Amazônicos, Programa de Pósgraduação em Desenvolvimento Sustentável do Trópico Úmido, Belém, 2009.

NÓBREGA, W. R. M. Turismo e políticas públicas na Amazônia brasileira: instâncias de governança e desenvolvimento nos municípios de Santarém e Belterra, Oeste do Estado do Pará, 2012. Tese (Doutorado em Ciências do Desenvolvimento Socioambiental) - Universidade Federal do Pará, Núcleo de Altos Estudos Amazônicos, Belém/Pa, 2012.

Turismo, desenvolvimento e políticas públicas: limites e avanços no Estado do Pará. In: AZEVEDO, F. F.; FIGUEIREDO, S. L; NÓBREGA, W. R. de M; MARANHÃO, C. H. da S. (ORG). Turismo em foco. Belém: NAEA, 2013. p. 11-27.

NÓBREGA, W. R. M.; FIGUEIREDO, S. L. Turismo e gestão pública: uma avaliação das instâncias de governança no Oeste do Estado do Pará. In: PIMENTEL; T. D.; EMMENDOERFER; M. L.; TOMAZZONI; E. L. (Orgs.). Gestão Pública do Turismo no Brasil, Teorias, Metodologias e Aplicações. Caxias do Sul - RS: EDUCS, 2014. p. 425-449.

Olival, A. de A.; SPEXOTO, A. A.; RODRIGUES J. A. Participação e cultura política: os conselhos municipais de desenvolvimento rural sustentável no território Portal da Amazônia. Rev. Econ. Sociol. Rural, v. 45, n. 4. Brasília, Out./Dec.2007.

OLIVEIRA, F. T. C.; ZOUAIN, M. D.; BARBOSA, M. G. L. Políticas públicas de turismo en Brasil: Una evaluación en 65 municipios. Estudios y Perspectivas en Turismo, v. 24. 2015, p 76-95.

PARÁ. Plano estratégico de turismo - Plano Ver-o-Pará. Pará, 2011.

PARÁ. Plano de Desenvolvimento Regional do Tocantins - PDRS. Resumo Executivo. Pará, 2009.

SCHNEIDER, V. Redes de políticas públicas e a condução de sociedades complexas. Civitas, Porto Alegre, v. 5, n. 1, jan./jun. 2005, p. 29-58.

SILVA, P. L. B.; MELO, M. A. B. O processo de implementação de políticas públicas no Brasil: características e determinantes da avaliação de programas e projetos. NEPPUNICAMP. 2000, p. 2-16. Caderno n. 48.

SOUZA, M. L. O planejamento e a gestão das cidades em uma perspectiva autonomista. Território, Rio de Janeiro, v. 1, n. 8, p. 67-100, 2000. 
THIOLLENT, M. Crítica metodológica, investigação social e enquete operária. São Paulo, Livraria e editora Polis, 1987.

TOMAZZONI, E. L. Turismo e desenvolvimento regional: dimensões, elementos e indicadores. Caxias do Sul, RS: Educs, 2009.

Recebido em: 19-06-2015.

Aprovado em: 19-07-2015. 